\title{
NOTES ON BOMBYCID LARVAE.-I.
}

\author{
BY HARRISON G. DY $\Lambda$ R, NEW YORK, N. Y.
}

Nola ovilla Grote.

1875. Grote, Can. ent., 7, 221.

1884. Packard, Amer. nat., 18, 726.

Larva. Dr. Packard makes the following statements: "It differs from Arctian and Lithosian larvae in having one less pair of abdominal legs. The body is broad and much flattened, rather short, with four pairs of well developed abdominal feet; the first pair being situated on the fourth abdominal segment. The body is hairy, though not densely so; on each segment are four dorsal tubercles, from which radiate short dusky hairs; on the side is a larger and longer tubercle from which arise lateral, very long hairs. Length $13 \mathrm{~mm}$."

Cocoon. "Boat-shaped, flattened, oval cylindrical, closely attached to the surface of a leaf. It is composed of silk, covered closely on the inside with bits of oak leaves."

\section{Nola trinotata Walker.}

1866. Walk., Cat. Brit. mus., pt. 35, pg. 1902, Lebena.

r89r. Butler, Insect life, v. 3, p. 297, sexmaculata Grote.

I877. Grote, Can. ent., v. 9, p. 235 . Nola.

I8go. Dyar, Insect life, v. 3, p. 6r.

Larva. I have elsewhere described this larva. It is a thick, somewhat flattened insect, the last segment small, the abdominal feet consisting of but four pairs, as in the preceding. It is furnished with piliferous warts as above. It lives exposed upon the surface of the leaves, forming no web.

Cocoon. Curiously constructed of little pieces of bark laid together like bricks. It is interesting to watch the larva forming its cocoon, which it does by building up two parallel walls by spinning the little pieces of outer bark together by their edges, and sub- sequently drawing them together from the inside. 'The pieces of bark are bitten off the branch on which it forms its cocoon.

\section{Nola hyemalis Stretch.}

1885. Stretch, Ent. amer., I, 102.

Larva. Congeneric with the above. Body flattened, wider than high, tapering very slightly to the extremities; abdominal feet present only on the 4 th, $5^{\text {th }}, 6$ th and Ioth abdominal segments. Head small, pale testaceous, whitish above the mouth with brownish marks at the sides; ocelli black. Body pinkish, cervical shield bisected, dark; three rows of piliferous warts on each side as in $N$. sexmaculata. The upper two are brownish and bear short hairs; the third row (lateral) is orange, and bears long, whitish hairs. On the body is an interrupted dorsal and waved subdorsal line, and brown dorsal shades connected with the lines; spiracles black; length of larva $10 \mathrm{~mm}$.

Cocoon. Not strong, composed entirely of silk, and not firmly fastened to a support. It is elliptical, opaque white. The pupa is without cremaster, light brown, and pilose.

I found a number of these larvae on willow near Phœnix, Arizona, in November, 1889.

Nola sorghiella Riley.

1882. Riley, Report U. S. dep. agr., 187, pl. II.

Larva. This is congeneric with the preceding species, as may be seen from Prof. Riley's figures. It is of the same general shape, and has the characteristic four pairs of abdominal feet, but differs from the other species strikingly in habit, as the larvae appear to live socially in a web.

These four species of Nola are the only ones of which the larvae are known, so far as I am aware. 


\section{Orgyia definita Packard.}

1864. Packard, Proc. ent. soc. Phil., 3, 332.

1888. Lintner, $4^{\text {th }}$ rept. N. Y. state entom., p. 50 .

I89r. Thaxter, Can. ent., 23, 34 .

This species has six stages in larvae that produce male moths, and seven stages for female moths. I have observed all but the first of these stages, and the life history, as far as I have made it out, is as follows :-

Egg. Nearly spherical, the top a little flattened; a large, central, brownish spot with a paler dot at the apex of the egg, surrounded by a concentric concolorous ring; diameter $\mathrm{I} \mathrm{mm}$. The eggs are laid in masses on the cocoon of the female moth, but are not naked as in the $O$. nova, nor covered with froth as in $O$. leucostigma, but with the hairs from the body of the moth, which are rubbed on by the female before it dies. The eggs are gummed together, and the hair also adheres to them. The winter is passed in this stage as with the allied species.

First stage. Not observed.

Second stage. Head pale whitish, width 0.7 $\mathrm{mm}$. Ocelli black, mouth brown. The warts on the body are small, except a large pair on joint 2 , which bear two or three short plumed black hairs; a few more of these hairs arise dorsally on joint 12 . The other warts bear a few long white hairs. The body is pale whitish, the retractile warts on joints ro and I I whitish. There are traces of the two anterior of the four dorsal, brush-like tufts which are seen in the mature larva on joints 5-8. Even in this early stage the characteristic markings of the mature larva are developed, though somewhat indefinitely.

Third stage. Head pale yellowish, jaws black; width $\mathrm{r} \mathrm{mm}$. The warts are arranged as in the mature larva, small, concolorous with the body, the large ones on joint 2 bear. ing thin pencils of plumed black hairs. A similar pencil, mixed with shorter brown hairs, arises from joint 12 . The body is pale whitish, with a yellowish subdorsal band on the posterior segments and a stigmatal band running the whole length, wider on joints 5,6 , and 7 . Three dorsal, deep yellow tufts on joints 5,6 , and 7 respectively. The warts bear thin, whitish hairs; the dorsal retractile ones on joints Io and II are whitish with a blackish shade around them. Length of larva Io $\mathrm{mm}$.

Fourth stage. Head as before, with a small brown shade above the mouth; width $1.5 \mathrm{~mm}$. The body differs only in being shaded with blackish dorsally and laterally. The yellow tufts are now four in number on joints $5-8$. The cervical shield is pale yellow like the head.

Fifth stage. Width of head 2.I $\mathrm{mm}$. Between the yellow dorsal tufts are a series of velvety black spots, concealed unless the insect is disturbed. The dorsum is gray, broadly so anteriorly, but partly replaced by a yellow subdorsal band on joints 9-13. The lateral region is gray, the warts whitish and partly surrounded by yellow. A narrow stigmatal band. Otherwise as before.

Sixth stage ( $\delta$ mature larva). Head pale yellow, shiny, the labrum and antennae white; width $2.8 \mathrm{~mm}$. Body pale yellow, a pale, almost colorless, dorsal band, replaced on joint 2 by the pale yellow cervical shield containing two darker yellow warts, narrow and greenish on joints 3 and 4 , widening and enclosing the yellow dorsal brush-like tufts on joints 5-8, narrowed on joints 9-I 2 enclosing the concolorous retractile tubercles, and absent on joint I3. A narrow subdorsal and fainter stigmatal, similarly colored lines. These bands are in some specimens more or less blackish, or black, blue-gray, or dark brown, and there is a velvety black spot between the dorsal tufts on joints 6,7 and 8 . The warts are all pale yellow; the pencils on joint 2 are long, plumed, black; that on joint I 2 of light brown hair with a few long black plumed ones on its posterior side. The other hair is long, thin and white.

The larva does not differ structurally from O. leucostigma, but differs markedly in color. 
Seventh stage ( $q$ larvae only). Head pale yellow minutely mottled with grayish spots; labrum, antennae and a spot before the eyes, white; ocelli and jaws black; width $3.5 \mathrm{~mm}$. The body is as in the previous stage, but the warts on the cervical shield are not distinctly darker. The dorsal blackish or pale gray shade is in triplicate on joints 3 and 4. Spiracles white in a fine black border. The body is often bright yellow, as are the dorsal tufts, and even the hair is yellowish.

Cocoon. Double, thin, made of silk and the hairs of the larva.

of Pupa. Cylindrical, the abdominal segments tapering, the eyes, wing cases and antenna cases especially prominent; a little depressed behind the thorax. Semi-transparent, shiny yellowish white, the back covered with long, thin, silky white hairs; cremaster flat, terminating in several brown hooks well fastened in the silk of the cocoon. Length $12 \mathrm{~mm}$.; width $5 \mathrm{~mm}$.

o Pupa. Robust, thickest through the 2nd to 4 th abdominal segments, elsewhere smaller, of nearly even width; thorax and head small, no wing cases, leg cases small. Last segment rounded, cremaster flat, rather broad at base, terminating in a number of brown divergent hooks. Color semitransparent, shiny, very pale yellowish, without marks. Over the dorsum considerable fine, rather long, whitish silky hair. Length 18 mm., greatest diameter $8 \mathrm{~mm}$.

O Imago. Of the same structure as $O$. leucostigma, but not white, the color of the down, which is especially abundant on the ventral side, being light brown. A small black spot on the second abdominal segment. The rudimentary wings are dark cinereous. The $\delta$ imago is very similar to $O$. leucostig$m a$, but can be distinguished by its darker color and heavier black markings.

Food plants. Dr Thaxter gives oak, but I have found the species as omnivorous as $O$. leucostigma. My specimens were fed mainly on maple and witch-hazel.

\section{THE GERM-BAND OF INSECTS.*}

Those who have watched the advance in our knowledge of insect embryology during the past three or four years will be deeply interested in Prof. Graber's latest treatise. Like his muscid paper it represents many years' study, but unlike that work it covers a very considerable ground, being a comprehensive description of the germ-band of a number of insects. The species investigated belong to the genera: Lina, Lema, Telephorus, Melolontha, Hydrophilus; Pieris, Gastropacha, Bombyx, Zygaena; Hylotoma; Stenobothrus, Mantis, and Gryllotalpa. It will be seen that this list comprises repre-

\footnotetext{
* Vergleichende studien am keimstreif der insecten, von Veit Graber. Denkschr. d. math. naturwiss. $c^{\text {lasse d. k. akad. d. wiss. Wien. Bd. } 57,1890,621-}$ 734. 12 colored plates. $4^{\circ}$.
}

sentatives of four of the important orders. Prof. Graber treats of the formation and method of growth of the germ-band, its relations to the envelopes (amnion and serosa), its segmentation (both internal and external) and its appendages. Chapters are introduced on the formation of the germ-layers and on the origin of the body spaces. Many pages are given up to a minute and critical discussion of the results achieved by other investigators. The work concludes with a long chapter on the development of the nervous system.

In a brief sketch we cannot hope to do justice to the mass of matter with which Prof. Graber presents us; it will be possible to touch on only a few of the questions with which he attempts to deal. Before so doing 

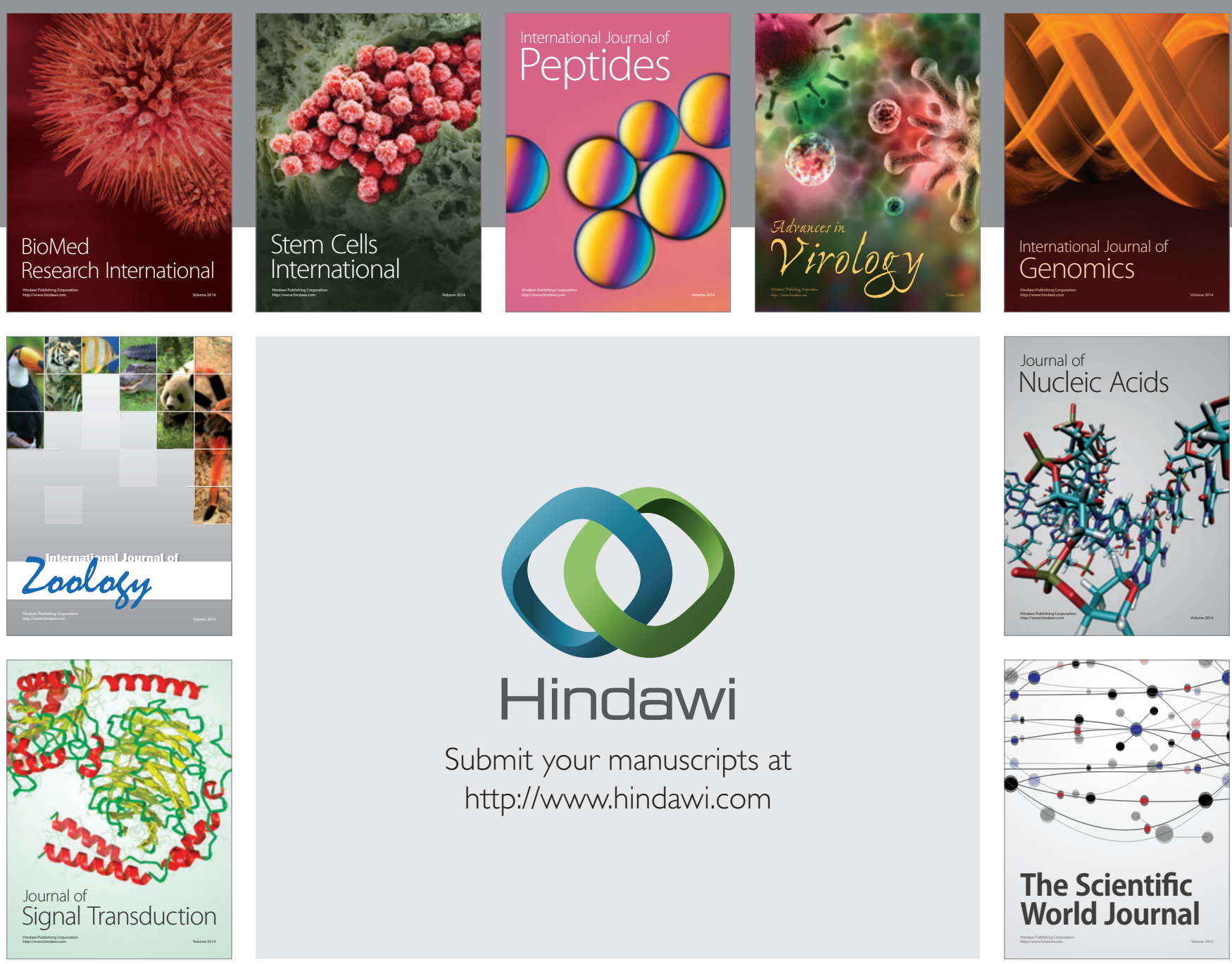

Submit your manuscripts at

http://www.hindawi.com
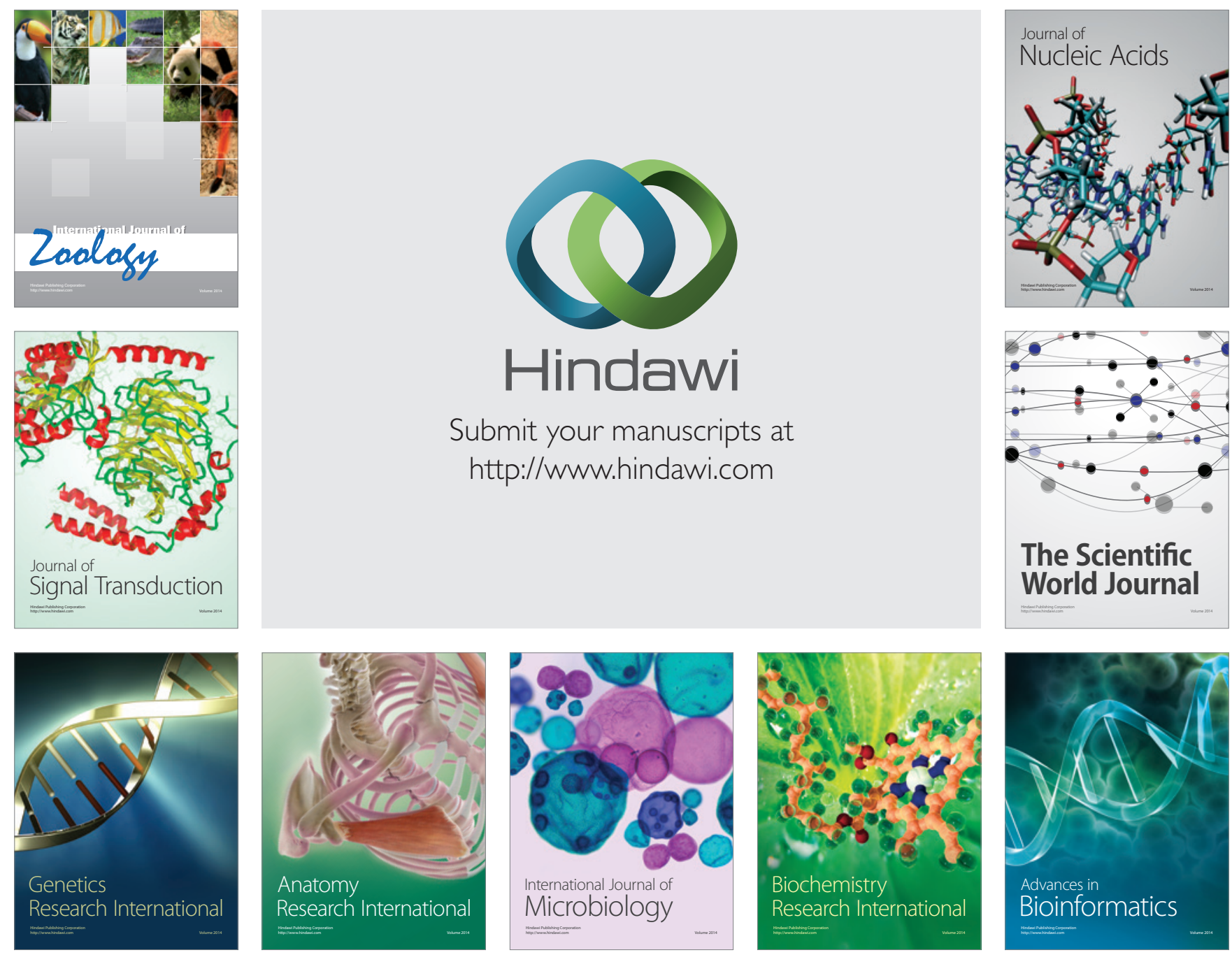

The Scientific World Journal
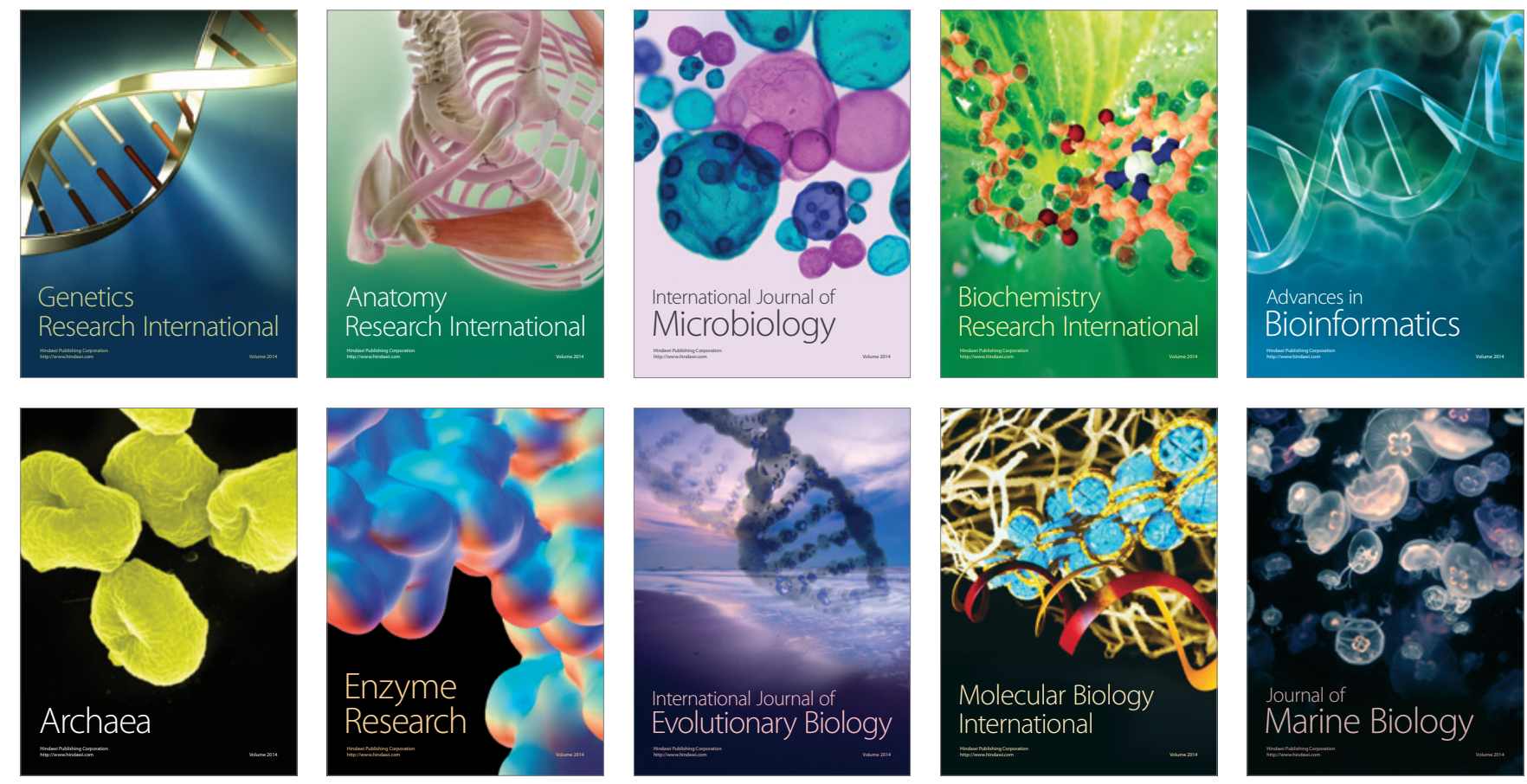